removed by litholapaxy. The bladder was washed out daily, with the result that the urine became acid, but there was no diminution in the pus or frequency.

On December 16th Mr. Bickersteth, of Liverpool, and others being present, I removed the prostate. There was considerable difficulty in opening the bladder suprapubically. owing to the scar tissues being matted together, and still greater difficulty in enucleating the prostate, owing to the inflammatory adhesions, resulting from the previous operation, between the inner margins of the prostate and the walls of the bladder, though the gland came away readily from the triangular ligament. A portion of the prostatic urethra came away adherent to the gland. Uninterrupted recovery. The wound was closed lecember 29 th, thirteen days after the operation. The patient is now quite well, walking about the wards, able to retain and pass his urine as well as he ever did.

The prostate (Fig. 4, p. 1186 ), which weighs $x_{4}^{\prime} \mathrm{oz}$., is jagged along the posterior aspect of the right lobe, where it was adherent to and matted with the bladder wall. This is the third case in which my operation of complete enucleation of the prostate has been entirely successiul after McGill's operation had failed. The previous operator in this case has persistently in his writings and otherwise minimized and misrepresented the nature and scope of my operation, as being identical with McGill's. It is the irony of fate that this case, in which Mecill's operation performed by him had entirely failed to bring relief to the patient, should have fallen into my hands to be completely cured by total extirpation of the prostate.

$$
\text { CAse LXXirr. }
$$

A gentleman, aged 76 , sent by Dr. T. D. Griffiths, Swansea, seen with Dr. Homerton, London, December $x_{5}$ th, 1903 . Prostatic symptoms for three years : retention ten months ago; catheter employed since then with much pain in passing it; great irritability of the bladder; cannot sleep from the frequency of mieturition; urine acid but contains much pus and mucus; prostate greatly enlarged, smooth, soft, movable, felt bimanually ; patient's health much impaired.

On December rgth, Mr. Thomson Walker and Dr. Homerton assisting, I removed the prostate, weighing $4 \frac{3}{4} 0 \%$, as usual. There was very little bleeding or shock. The patient has had no bad symptom, and is now convalescent.

Note.-During the period that has elapsed since this lecture was delivered on January 6th, 1904, I have performed this operation in a be submitted for the consideration of the prolession.

REFERENCES.

1 July 2oth, rgor. 2 February rst, July 26th. and November 8 th, 1902 April i8th, July 4 th, and October 17 th, 1903 . 3 BRITISH MEDICAL JOURNAL, October 17 th, 1903.

\section{TOTAL PROSTATECTOMY}

DEDUCTIONS TO BE DRAWN FROM THE PRESENCE OF STRIATED MUSGLE FIBRE IN THE "GAPSULE" OF THE PARTS REMOVED.

BY CUTHBERT S. WAL:ACE, B.S., F.R.C.S., Assistant Surgeon to St. Thomas's Hospital and the East London Hospital for Children.

Mr. Thomson WALKer, in a recent communication read before the Royal Medical and Chirurgical Society, ${ }^{\prime}$ has drawn attention to the presence of striped muscle fibre on the anterior aspect of the prostate. He describes it as surrounding the apex of the organ and then as passing up on the anterior surface of the gland between the "capsule" and the posterior layers of the recto-vesical sheath of the prostate. (The prostatic plexus of veins lies between the layers of the recto-vesical fascia; consequently there will be a layer of the recto-vesical sheath between the veins and the layer of striped muscle.) In another part of the same paper, when describing the "capsule" on a specimen removed by prostatectomy, it was stated that striped muscle fibre was found in the anterior part of the "capsule." From this it was argued that the line of cleavage in the process of enucleation must have passed outside the confines of the gland, and that therefore the prostatectomy was complete.

In microscopic sections of the normal prostate made at right angles to the long axis of the urethra and midway between the extremities of the gland, the following features in the relation of this striated muscle may be noted.

At the most anterior part of such a transverse section the striated muscle fibres take a transverse or horizontal direciion. The bundles are well marked and are separated from each other by a little fine areolar tissue. Near the urethra the bundles become more widely separated, and between them are seen to lie well-marked fibrous tissue and unstriped muscle fibres. Traced outwards towards the lateral parts of the prostate, the striped muscle fibres lose themselves in the substance of the organ. Passing inwards towards the urethra the striped muscle fibres become more and more widely separated by the fibro-muscular stroma of the gland until at last the latter predominates, the striped fibres becoming fewer and fewer until they cease altogether. Some time, however, before this happens the gland tissue makes its appearance, so that striped muscle fibre, fibro-muscular stroma, and gland tissue are found in the same field; and it is possible to see gland tissue with striped muscle fibres lying on both its central and peripheral aspect, so intimately is the striped fibre insinuated into the peripheral portion of the gland.

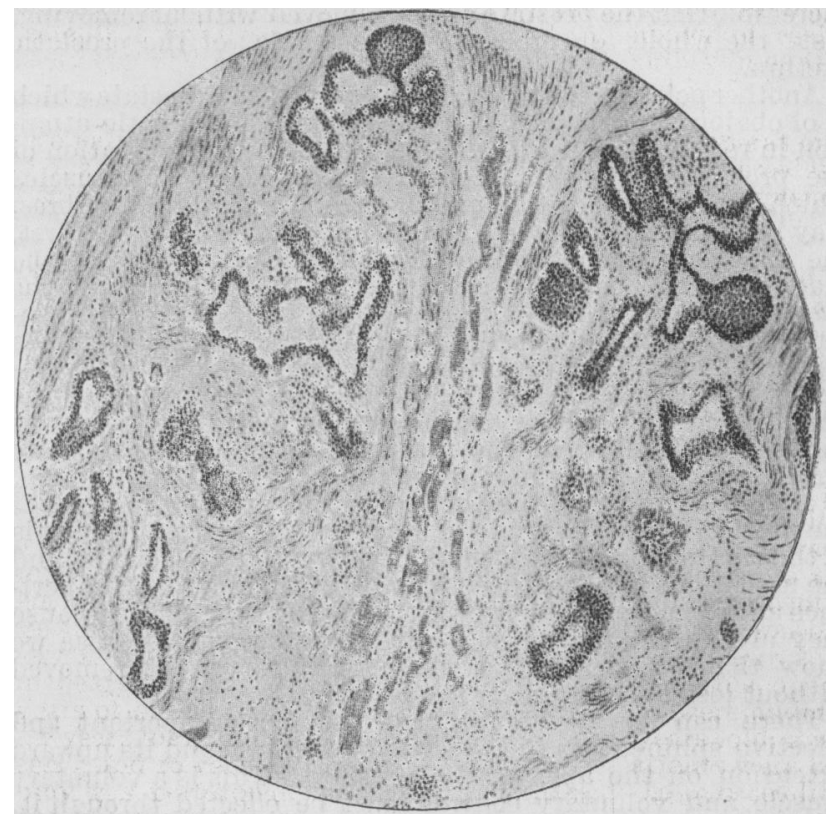

Fig. 1.-Showing a portion of the periphery of the prostate of a young adult. $\Lambda$ group of striated muscle fibres is seen penetrating the stroma between the gland acini.

It thus foliows that the presence of striped muscle fibre in the "capsule" of an enurleated prostate is not to be taken as an irrefragable proof that the line of enucleation has passed outside the confines of the gland, and that therefore the prostatectomy is complete. The completeness, as in other cases, can only be established by a microscopic demonstration of the absence of gland tissue in the parts left behind.

REFERENCE.

1 BRITISH Medical JouRnal, March 26th, 1904, p. 728.

\section{THE RELATIVE ADVANTAGES OF SUPRAPUBIC aNd PERINeal PRostatectomy.*}

By EDWARD DEANESLY, B.Sc.LoNI., F.R.C.S.EN(i., Honorary Surgeon, Wolverhampton and Staffordshire General Hospital.

THE prostate must be regarded both anatomically and functionally as an accessory portion of the urethra, to which it is inseparably attached. Its relation to the bladder is much less intimate. The normal prostate is entirely extravesical, and its internal projection within the bladder is hardly visible when the bladder and urethra are slit open from the front. Seen in their normal relations in the living body by means of the cystoscope, the difference between the male and female bladders is much less than would be expected, and all that is seen of the prostate is a low median-grooved projection at the posterior part of the orifice of the urethra. The median groove corresponds to the anterior aspect of the projecting uvula vesicae, and in some cases the uvula itself is seen as a small round projection in the middle of the groove.

The prostatic urethra, $\mathrm{I}_{4}^{1}$ in. in length, is completely embraced by the prostate, but a much thicker portion of prostate covers it behind than in front. Moreover, the anterior portion consists mainly of unstriped muscular fibres, and in some cases no gland tissue at all exists in front of the urethra. The prostatic utricle and seminal ducts open into the projecting veru montanum near the centre of the prostatic urethra, and above the centre are the openings of the prostatic ducts. The connexion of the urethra with the surrounding prostatic

* Read beiore the Staffordshire Branch of the British Medical Association. 